\title{
Nilai Budaya Dan Nilai Agama Masyarakat Suku Sasak Dalam Tata Cara Pengurusan Jenazah Di Desa Kerumut Kecamatan Pringgabaya (Sebuah Studi Komparasi)
}

\author{
Alpan Ahmadi \\ Institut Pendidikan Nusantara Global \\ Alpansori90@gmail.com
}

\begin{abstract}
This research aim to for the descreption of cultural value and religion value procedures management of corpse, thehe are some tradition executed by society which disagree with teaching of religion Islam. According to condifidence of society, people soul die not yet gone far until day the ninth, however there is still around its house, therefore, family gambled dedupe. Pursuant to problem to above obyek becoming research target is cultural value in last offices tradition in putting dedupe for people to die which is donel conducted by society of Kerumut. Cultural value implied procedures management of the corfse in fact do not lessen existing value in religion teaching of islam. Because at the time of managing corpse from dying buried do not go out from religion teaching. Society still hold firmly with religion teaching of islam while the executed culture only left by trust is run ancestors hitherto.
\end{abstract}

Keyword: Culture Value, Religious Value, Sasak Tribe

\section{PENDAHULUAN}

Penyelenggaraan upacara adat oleh suatu masyarakat merupakan bagian dari kebudayaan dan menyangkut kepercayaan masyarakat. Penyelenggaraan adat ini mempunyai fungsi sosial yang penting antara lain untuk memberitahukan kepada khalayak ramai mengenai perubahan tingkat hidup yang telah dicapai.

Sebagai mahluk sosial manusia tidak dapat lepas dari keberadaan orang lain dalam hidupnya, karena manusia tidak dapat memenuhi kebutuhannya sendiri baik kebutuhan material maupun spiritual. Jadi manusia membutuhkan bantuan dari manusia lain untuk saling mengisi satu sama lain dan dapat bekerja sama dengan baik sehingga tercipta hubungan yang harmonis antara anggota masyarakat dalam kehidupan supaya apa yang menjadi tujuan bersama dapat tercapai tanpa adanya saling menyakiti.

Supaya hubungan dan kerja sama tetap terjalin dengan baik diantara anggota masyarakat dalam kehidupan sehari-hari, hendaknya setiap anggota masyarakat tidak melakukan hal-hal yang merusak hubungan yang sudah dibina bersama dengan masyarakat lainnya dan tidak melakukan perbuatan yang melanggar niai agama dan norma-norma yang ada dalam masyarakat yang tertulis maupun yang tidak tertulis.

Peraturan yang tidak tertulis tersebut dipelihara oleh anggota masyarakat secara turun temurun dan bersifat tradisional, meskipun demikian ada akibat yang diterima jika peraturan atau norma itu dilanggar, oleh karena itu sebagai bagian dari masyarakat yang harus mentaati aturan yang ada supaya tercipta hubungan selaras, serasi, dan seimbang diantara anggota masyarakat lainnya.

Sehubungan dengan perkembangan zaman budaya juga ikut bergeser dari semula mengacu pada agama sekarang sedikit bergeser dengan adanya budaya dari luar masuk dan ikut memberikan corak terhadap budaya dan agama yang ada di Indonesia.Budaya-budaya yang masuk tersebut ada yang sesuai dan ada yang tidak sesuai dengan budaya dan agama yang ada.Perkembangan yang terlalu berlebihan dapat menjadi ancaman bagi manusia yang masuk tidak dipilih untuk dicontoh atau diikuti.

Apabila diperhatikan, aktualisasi ajaran agama Islam yang berkembang di dalam masyarakat Sasak, akan terlihat berbagai penyimpangan dan pergeseran dari nilai-nilai Islam, terkadang tidak sesuai dengan ajaran Islam dalam proses adat yang dilaksanakan.Dalam kaitan ini, masyarakat 
Sasak yang rata-rata memeluk Islam ini, pada umumnya menyelenggarakan upacara kematian sejalan dengan tuntutan Islam, tapi terdapat diantara mereka yang menerapkan secara tidak murni karena masih tercampur dengan praktik ajaran lain, seperti adanya sesajen dan lain sebagainya (Ahmad Abd Syakur, 2006: 292).

Dalam proses upacara kematian jenazah ada beberapa tradisi yang dilaksanakan oleh masyarakat yang tidak sesuai dengan ajaran Islam. Dalam tata cara pengurusan jenazah dari hari ke pertama sampai hari kesembilan salah satu keyakinan mereka adalah, ruh mayit tersebut belum pergi jauh, akan tetapi masih ada disekitar rumahnya. Oleh karena itu, keluargaselalu mempersiapkannya dedupe (seporsi makanan lengkap terdiri dari nasi, sayur, lauk, lengkap dengan cuci tangan, minuman dan di bakar kemenyan di tempat menaruh makanan tersebut). Dedupetersebut selalu diganti setiap datang waktu makan, keluarga menaruhnya ditempat biasa jenazah tidur sebelum meninggal dunia, makanan ini dikenal dengan istilah nasi pelayaran. Hal ini terus dilakukan setiap hari, sampai datangnya hari kesembilan terhitung dari wafatnya almarhum.

Penyimpangan tersebut pada hakikatnya merupakan semacam pergeseran nilai-nilai Islam dari yang bersifat positif (tekstual) kepada yang bersifat negatif (kontekstual). Hal tersebut akan tampak dari adanya pergeseran perilaku budaya yang positif kepada prilaku budaya yang negatif di kalangan masyarakat (Ahmad Abd Syakur, 2006: 354).

Bagi masyarakat pedesaan tradsional adat istiadat keagamaan memiliki daya pengikat tersendiri.Meninggalkan tradisi berarti mengancam kelanggengan eksistensi masyarakat. Islam yang hidup dalam masyarakat tertentu harus mampu bergulat dengan adat istiadat tradisional yang umumnya bersendi pada kepercayaan mitodologi. Dalam pergulatan ini sangat mungkin unsur-unsur Islam dihilangkan untuk tradisi budaya.Mungkin pula Islam ditumpangi oleh unsur tradisi lama. (Roibin, 2009 : 103).

Hakikatnya antara agama dan budaya sangatlah jauh perbedaannya, budaya merupakan hasil dari buatan manusia dimana budaya tersebut dapat berubah seiring dengan berjalannya waktu sedangkan agama adalah sesuatu yang hak tidak bisa dirubah karena agama datangnya dari Allah SWT dan RasulNya.

\section{METODE PENELITIAN}

Jenis penelitian yang digunakan adalah penelitian kualitatif yaitu metode penelitian yang digunakan untuk meneliti pada kondisi obyek yang alamiah (Sugiyono, 2010:1). Metode yang digunakan, yakni desktif kualitatif. Adapun data teradiri dari data primer dan sekunder. Data primer adalah Sumber data yang langsung memberikan data kepada pengumpul data (Sugiyono, 2010: 62). Data sekunder adalah Sumber yang tidak langsung memberikan data kepada pengumpul data, misalnya lewat orang lain atau lewat dokumen (Sugiyono, 2010: 62).

Menurut Sanafiah Faisal (dalam Sugiyono, 2010: 56-57) yang dinyatakan sebagai informan, sebaiknya memenuhi kriteria sebagai berikut: Mereka yang menguasai atau memahami sesuatu melalui proses enkulturasi, sehingga sesuatu itu bukan sekedar diketahui, tetapi juga dihayatinya, Mereka yang tergolong masih sedang berkecimpung atau terlibat pada kegiatan yang tengah diteliti, Mereka yang mempunyai waktu yang memadai untuk dimintai informasi, Mereka yang tidak cenderung menyampaikan informasi hasil "kemasannya" sendiri dan Mereka yang pada mulanya tergolong "cukup asing" dengan peneliti sehingga lebih menggairahkan untuk dijadikan semacam guru atau narasumber. Teknik pengumpulan data merupakan langkah yang paling strategis dalam penelitian, karena tujuan utama dari penelitian adalah mendapatkan data. Tanpa mengetahui teknik pengumpulan data, maka peneliti tidak akan mendapatkan data yang memenuhi standar data yang ditetapkan (Sugiyono, 2010: 62).

\section{PEMBAHASAN}

Pengertian "Nilai" Kaelan (dalam Fauzie Nurdin, 2010: 40), nilai adalah kualitas yang melekat pada suatu objek, bukan objek itu sendiri. Sesuatu itu mengandung nilai jika ada sifat atau kualitas yang melekat pada sesuatu 
itu. Berarti "pada hakikatnya sesuatu itu bernilai bagi dirinya sendiri. Segala sesuatu itu pada hakikatnya bernilai, hanya nilai macam apa saja yang ada serta bagaimana hubungan nilai tersebut dengan manusia”. Secara aksiologi, sebagai contoh nilai persaudaraan tentu berguna jika dipahami dengan benar dan teraktualisasi dalam kehidupan keseharian, bermanfaat bagi manusia sebagai individu, keluarga, kelompok sosial, komunitas maupun masyarakat didasarkan nilai kerohanian, nilai religius, nilai persaudaraan, atau kesadaran bersama (Fauzie Nurdin, 2010: 41).

Menurut Perry dan Pepper (dalam Munandar Sulaeman, 2007:35) Nilai adalah sesuatu yang menarik bagi manusia sebagai objek. Nilai adalah segala sesuatu tentang yang baik atau yang buruk.

Kebudayaan berasal dari bahasa sanksekerta, yaitu budaya yang merupakan bentuk jamak dari buddhi (budi atau akal) diartikan sebagai hal-hal yang berkaitan dengan budi dan akal (Koentjaraningrat, 2009: 146). Kebudayaan adalah cara hidup tertentu, yang memancarkan identitas tertentu pula pada suatu bangsa. Kebudayaan dapat pula diartikan sebagai upaya masyarakat untuk terus menerus secara dialektis menjawab setiap tantangan yang dihadapkan kepadanya dengan menciptakan berbagai prasarana dan sarana, pada intinya budaya adalah proses terus menerus menyimak kadar dinamika dari sistem nilai dan sistem kepercayaan yang mapan dalam masyarakat (Hans J Daeng, 2008: 45).

Menurut Edward B. Tylor (dalam Ahmad Abd. Syukur, 2006 : 6-7). mengatakan pengertian kebudayaan adalah kompleks yang mencakup pengetahuan, kepercayaan, kesenian, moral, hukum, adat-istiadat, dan kemapuankemampuan serta kebiasaan-kebiasaan yang didapatkan oleh manusia sebagai anggota masyarakat. Budaya adalah suatu konsep yang membangkitkan minat. Secara formal budaya didefinisikan sebagai tatanan pengetahuan, pengalaman, kepercayaan, nilai, sikap, makna, hirarki, agama, waktu, peranan, hubungan ruang, konsep alam semesta, objek-objek materi dan milik yang diperoleh sekelompok besar orang dari generasi ke generasi melalui usaha individu dan kelompok (Deddy Mulyana dan Jalaluddin, 2010: 18). Secara sederhana, budaya merupakan hasil tindakan kreatif rasionalitas manusia (Muhammad In'am Esha, 2011:3).

Menurut (KBBI, 2006: 669) tradisi adalah adat kebiasaan yang diturunkan dari nenek moyang yang dijalankan oleh masyarakat. Beberapa upacara yang berhubungan dengan lingkungan hidup manusia yang dimulai dari peristiwa kelahiran sampai kematian. Selain itu juga mengadakan sesaji dan selamatan melalui upacara-upacara tertentu yang berkaitan dengan aktifitas hidup mereka sehari-hari. Tradisi dipahami sebagai suatu kebiasaan yang telah tertanam dalam masyarakat Muslim Lombok (Masnun, 2007: 214). Dari pengertian tentang tradisi di atas dapat disimpulkan bahwa tradisi adalah kebiasaan masyarakat baik itu berupa adat istiadat atau budaya yang sudah turun temurun dilaksanakan sesuai dengan kebiasaan masing-masing masyarakat.

Ada tiga istilah yang menunjukan pengertian Agama, yaitu agama itu sendiri, religi, dan istilah din. Secara etimologis, pengertian agama yang berasal dari bahasa sansekerta terdiri dari a=tidak, dan gam= pergi, berarti tidak pergi, tetap, statis, sudah ada sejak lama, menjadi tradisi, diwarisi secara turun temurun. Agama dari kata gam berarti kitab suci, tuntunan, atau pedoman. Maka agama adalah ajaran yang berdasarkan kitab suci, sesuatu yang dijadikan pedoman atau pegangan hidup manusia. Adapun pengertian lain, agama, dari kata $a=$ tidak, gama $=$ kacau, jadi agama adalah suatu sistem kehidupan yang tertib, damai, dan tidak kacau. Dengan demikian, dapat dikatakan bahwa agama adalah suatu ajaran yang sudah ada sejak dahulu, diwarisi secara turun temurun yang berfungsi sebagai pegangan dan pedoman hidup yang bersumber dari kitab suci agar kehidupan manusia menjadi damai, tertib, dan tidak kacau (Muhammad Harfin Zuhdi dkk, 2011: 70-71).

Semiotik (semiotika) adalah ilmu tentang tanda-tanda. Ilmu ini menganggap bahwa fenomena sosial/masyarakat dan kebudayaan itu merupakan tanda-tanda (Rachmat, 2011: 119). Menurut Peirce (dalam Mansoer, 1996: 32) setiap hari manusia menggunakan tanda untuk berkomunikasi. Di dalam penelitian 
kualitatif, teori semiotik dipandang sesuai oleh peneliti dalam hal yang menjadi inti kajian penelitian dalam nilai budaya dalam tradisi upacara kematian yaitu menaruh dedupe (nasi pelayaran) untuk orang yang sudah meninggal yang dilakukan oleh masyarakat di Desa Kerumut Kecamatan Pringgabaya. Semiotik adalah ilmu tanda-tanda.

Tanda memiliki dua asfek yaitu Penanda (signifier) dan petanda (signifzed) penanda adalah bentuk formalnya yang menandai sesuatu yang disebut petanda, sedangkan petanda adalah sesuatu yang ditandai oleh penanda itu yaitu artinya. Contohnya kata "ibu" merupakan tanda berupa satuan bunyi yang menandai arti:'orang yang melahirkan kita' (Rachmat, 2011: 119-120).

Tanda itu tidak hanya satu macam saja, tetapi ada beberapa berdasarkan hubungan antara penanda dan petandanya. Jenis-jenis tanda yang utama adalah ikon, indeks, dan symbol.

Ikon adalah tanda yang menunjukan adanya hubungan yang bersifat alamiah antara penanda dan petandanya, hubungan itu adalah hubungan persamaan, misalnya gambar kuda sebagai penanda yang menandai kuda (petanda) sebagai artinya. Potret menandai orang yang dipotret gambar pohon menandai pohon.

Indeks adalah tanda yang menunjukan hubungan kausa (sebab-akibat) antara penanda dan petandanya, misalya asap menandai api, alat penanda angin menujukan arah angin, dan sebagainya.

Symbol adalah tanda yang menunjukan bahwa tidak ada hubungan alamiah antara penanda dan petandanya. Hubungannya bersifat arbitrer (semau-maunya). Arti tanda ini ditentukan oleh konvensi.'ibu' adalah symbol, artinya ditentukan oleh konvensi masyarakat bahasa (Indonesia). Orang Inggris menyebutnya mother, Perancis menyebutnya la mere, dan seterusnya. Adanya bermacam-macam tanda untuk satu arti itu menunjukkan "kesemenamenaan" tersebut. dalam bahasa tanda yang paling banyak digunakan adalah symbol (Rachmat, 2011: 119-120).

Kondisi Geografis Desa Kerumut. Desa kerumut merupakan salah satu desa yang berada di wilayah Kecamatan Pringgabaya Kabupaten Lombok Timur Provinsi Nusa
Tenggara Barat. Desa Kerumut memiliki luas wilayah sekitar $342.00 \mathrm{ha} / \mathrm{m} 2$ dengan batas wilayah sebagai berikut:

Sebelah Utara : Desa Pohgading Timur

Sebelah Selatan : Desa Anggaraksa

Sebelah Timur : Selat Alas

Sebelah Barat : Apitaik

Desa Kerumut memiliki luas $342.00 \mathrm{ha} / \mathrm{m} 2$ berdasarkan penggunaan lahannya, tanah di Desa Kerumut sebagian besar digunakan sebagai lahan persawahan, lahan pemukiman, dan perkebunan. Sedangkan sisanya digunakan sebagai lahan perkantoran, bangunan, pemakaman, pendidikan, dan prasana umum lainnya. Untuk lebih jelasnya mengenai penggunaan lahan di Desa Kerumut, dapat dilihat pada tabel sebagai berikut:

Tabel 4.1: Potensi Penggunaan Lahan di Desa Kerumut tahun 2013

\begin{tabular}{|c|l|c|}
\hline No & Jenis Lahan & Luas (ha/m2) \\
\hline 1 & $\begin{array}{l}\text { Tanah } \\
\text { Persawahan }\end{array}$ & $184.95 \mathrm{ha} / \mathrm{m} 2$ \\
\hline 2 & $\begin{array}{l}\text { Tanah } \\
\text { Perkebunan }\end{array}$ & $59.73 \mathrm{ha} / \mathrm{m} 2$ \\
\hline 3 & $\begin{array}{l}\text { Tanah } \\
\text { Pemukiman }\end{array}$ & $44.30 \mathrm{ha} / \mathrm{m} 2$ \\
\hline 4 & Tanah Kuburan & $0.60 \mathrm{ha} / \mathrm{m} 2$ \\
\hline 5 & $\begin{array}{l}\text { Tanah } \\
\text { Pekarangan }\end{array}$ & $34.50 \mathrm{ha} / \mathrm{m} 2$ \\
\hline 6 & $\begin{array}{l}\text { Tanah } \\
\text { Perkantoran }\end{array}$ & $3.70 \mathrm{ha} / \mathrm{m} 2$ \\
\hline 7 & $\begin{array}{l}\text { Tanah Prasarana } \\
\text { Umum Lainnya }\end{array}$ & $14.22 \mathrm{ha} / \mathrm{m} 2$ \\
\hline & \multicolumn{2}{|c|}{ Total } \\
\hline
\end{tabular}

( Sumber Profil Desa Kerumut, tahun 2018) Berdasarkan tabel di atas, maka dapat diketahui bahwa penggunaan lahan yang paling luas di Desa Kerumut adalah lahan untuk pertanian karena dari tabel di atas luas tanah persawahan adalah $184.95 \mathrm{ha} / \mathrm{m} 2$.

Jumlah Penduduk Berdasarkan Jenis Kelamin dan Jumlah Kepala Keluarga tahun 2018

\begin{tabular}{|l|l|}
\hline Jumlah laki-laki & 2.244 orang \\
\hline Jumlah perempuan & 2.445 orang \\
\hline Jumlah total & 4.869 orang \\
\hline Jumlah kepala keluarga & $1.471 \mathrm{KK}$ \\
\hline Kepadatan penduduk & 739 per km \\
\hline
\end{tabular}

(Sumber Profil Desa Kerumut, tahun 2018) 
Penduduk Desa Kerumut pada tahun 2012 berjumlah 4.869 orang yang terdiri dari 2.244 jiwa penduduk laki-laki dan 2.445 jiwa penduduk perempuan yang terdiri dari 1.471 KK. Jumlah penduduk Desa Kerumut.

Melihat dan mencermati jumlah penduduk dengan sarana ibadah yang ada di Desa Kerumut merupakan komunitas yang religious khususnya agama Islam yang dianut. Dari jumlah 4869 jiwa dengan jumlah penduduk laki-laki 2244 orang, penduduk perempuan sebanyak 2445 orang dengan jumlah kepala keluarga 1471 jiwa merupakan penganut agama Islam, dan dapat disimpulkan $100 \%$ penduduk Desa Kerumut memeluk agama Islam. Kentalnya Suasana agamais di Desa kerumut tepatnya di dusun Benteng terlihat dari Setiap malam minggu di adakan pengajian, malam Rabu di adakan Syafaah, kemudian malam Jum'at di adakan Hiziban bertempat di Masjid Nurul Ittihad Benteng, dan semua itu rutin dilakukan setiap minggunya. Penduduk Desa Kerumut adalah penduduk yang mayoritasnya beragama Islam yang di pengaruhi oleh budaya yang telah diwariskan oleh nenek moyang terdahulu. Desa Kerumut memiliki beberapa budaya atau adat kebiasaan yang tergolong cukup banyak. Diantaranya adalah budaya sorong serah atau merari', ngurisang (acara empat puluh hari anak yang baru lahir), khitanan atau nyunatang, pelayaran dan bedupe untuk orang yang sudah meninggal. Budaya bedupe sangat erat sekali dengan nuansa percampuran antara agama Islam dengan Animisme atau kepercayaan orang tua sebelum datangnya agama Islam. Nilai budaya dalam upacara kematian yang ada di Desa Kerumut sangat kental dan masih di laksanakan sampai saat ini, hal ini dapat dilihat dari proses yang di lakukan masyarakat apabila ada salah seorang meninggal dunia, dari hari pertama sampai hari kesembilan.

Mulai dari pembuatan keranda, masyarakat menggunakan bambu dan menggunakan tali treng untuk mengikat bambu agar kuat, dan pembuatan keranda di lakukan dengan cara bergotong royong. Kemudian saat penggalian liang lahat (nepong tanaq) biasanya sebelas orang dan yang di butuhkan adalah cangkul, linggis, pisau, gelas, piring, dan uang (selawat), piring dan uang di bagi oleh orang yang menggali kubur. Dapat kita lihat juga pada saat memandikan jenazah selain memakai sabun masyarakat yang ada di Desa Kerumut juga menggunakan beberapa air antara lain:

air asam,

air bedurik,

air kemiri, dan

air kayu cendana.

Setelah jenazah selesai dimandikan jenazah kemudian di bokos (di kafani) dengan kain kafan dan di masukan kedalam keranda, setelah semuanya selesai jenazah dibawa ke mesjid untuk di shalatkan dan langsung di bawa ke pemakaman. Dari hari pertama sampai hari kesembilan keluarga yang di tinggalkan bedupe (seporsi makanan lengkap terdiri dari nasi, lauk, sayur mayur, dan air minum lengkap dengan cuci tangan, dan di dekat tempat makanan tersebut di bakar kemenyan) kepercayaan masyarakat Desa Kerumut ruh orang yang meninggal tersebut sebelum Sembilan hari masih ada di sekitar rumah dan butuh makan, pedupaan di sajikan setiap waktu makan yaitu pagi, siang, dan malam.

Pada hari ke tiga meninggalnya almarhum keluarga melakukan pesrayan (mesrak) barangbarang pesrayan adalah barang yang sudah di pakai oleh almarhum semasa hidupnya antara lain: piring, gelas, ponjol nasi', baju, celana, sarung, dulang nasi', minyak tanah, tugku, panci, sabun, sikat gigi, dan lain-lain. Kemudian pada hari ketujuh (pelayaran) pada acara tersebut keluarga menggantung makanan di tengah-tengah pintu dan tebu di taruh di atas pintu sebagai tempat meletakkan makanan, kemudian semua makanan tersebut di taruh di dalam keranjang, makanan yang di taruh adalah segala sesuatu yang sering di makan oleh almarhum semasa hidupnya makanan yang sering ditaruh di antaranya ayam panggang, jeruk,roti, pisang, ketupat, uang, gula dan lain sebagainya sesuai kemampuan keluarga almarhum, makanan itu di taruh dari malam pelayaran dan boleh di turunkan (di makan) pada pagi hari sekitar jam sepuluh.

Pada hari kesembilan keluarga melakukan zikiran dan pada sore harinya keluarga pergi ke pemakaman untuk meriri kubur (memasang mesan). Nilai agama yang terkandung dalam 
tata cara pengurusan jenazah pada masyarakat di desa kerumut adalah Walaupun tradisi yang di jalankan masyarakat Desa Kerumut masih kental dan di lakukan sampai sekarang, masyarakat tidak pernah meninggalkan ajarkan agama Islam karena itu adalah ajaran yang benar adanya yang datang dari Allah SWT sedangkan budaya yang di laksanakan itu hanyalah tradisi dari nenek moyang masyarakat yang ada di Desa Kerumut.

Nilai agama dalam tata cara pengurusan jenazah pada masyarakat di Desa Kerumut juga tidak pernah di tinggalkan, ini dapat di lihat pada saat memandikan jenazah, saat memandikan jenazah mereka yang biasa memandikan tersebut membaca shalawat sampai jenazah selesai di kafani. Setelah itu jenazah di masukan ke dalam keranda dan di bawa ke mesjid untuk di shalatkan, kemudian setelah jenazah selesai di shalatkan masyarakat mengantar ke pemakaman, sebelum jenazah di masukan ke liang lahat salah satu tokoh masyarakat azan di dalam kubur. Setelah jenazah di timbun tanah salah satu tokoh agama duduk di tengah-tengah kubur jenazah untuk talkin.Setelah itu bertakziah dan acara terahir melakukan zikir dan do'a untuk jenazah. Pasca penguburan jenazah keluarga mengadakan zikir dan do'a setiap hari sampai hari kesembilan untuk jenazah. Masyarakat mengurus jenazah sesuai dengan yang di ajarkan di dalam agama Islam, memandikan, mengkafani, menshalatkan, mengantar jenazah ke tempat peristirahan terahir, dan mengubur jenazah.

\section{SIMPULAN}

Nilai budaya yang terkandung di dalam tata cara pengurusan jenazah tersebut sebenarnya tidak mengurangi nilai yang ada di dalam ajaran agama Islam,karena pada saat mengurus jenazah dari meninggal sampai di makamkan tidak keluar dari ajaran agama Islam, masyarakat masih berpegang teguh dengan ajaran agamanya yaitu agama Islam. sedangkan budaya atau tradisi yang di laksanakn tersebut hanyalah ajaran yang di tinggalkan oleh nenek moyang dan masih di jalankan sampai sekarang.

Jadi dalam membandingkan nilai budaya dan nilai agama dalam tata cara pengurusan jenazah di masyarakat Desa Kerumut tidak ada yang berlebihan, baik dari tata cara tradisi ataupun tata cara pengurusan jenazah dalam agama Islam. Dalam pengurusan jenazah mulai dari memandikan, menshlatkan, sampai jenazah di masukkan ke dalam liang lahat tidak ada yang berlebihan baik dari segi nilai budaya ataupun dari nilai agamanya. Karena menurut masyarakat yang ada di Desa Kerumut semua tradisi yang di jalankan tersebut sunnah boleh di kerjakan boleh juga tidak di kerjakan.

\section{DAFTAR PUSTAKA}

Daeng J, Hans. 2008. Manusia, Kebudayaan dan Lingkungan. Yogyakarta: Pustaka Belajar

Esha, Muhammad In'am. 2011. Percikan Filsafat Sejarah dan Peradaban Islam. Malang : UIN-Maliki Press

Koentjaraningrat. 2009. Pengantar Ilmu Antropologi. Jakarta: Rineka Cipta

Masnun. 2007. Tuan Guru KH Muhammad Zainuddin Abdul Madjid, Gagasan dan Gerakan Pembaharuan Islam Di Nusa Tenggara barat. Jakarta: Pustaka Al-Miqdad

Mulyana, Dedi \& Jalaluddin. 2010. Komunikasi Antarbudaya, Panduan

Berkomunikasi Dengan Orang-Orang Berbeda Budaya. Bandung: PT. Remaja Rosdakarya

Nurdin, Fauzie.2010. Integralisme Islam dan Budaya Lokal, Relevansi Nilai-Nilai Filosofis Kebudayaan Bagi Pembangunan Daerah.Yogyakarta : Gama Media

Pradopo Djoko, Rachmat. 2011. Beberapa Teori Sastra, Metode Kritik, dan Penerapannya. Yogyakarta: Pustaka Belajar

Roibin.2009. Relasi Agama \& Budaya Masyarakat Kontemporer. Malang: UIN-Malang Press

Sugiyono. 2010. Memahami Penelitian Kualitatif. Bandung: Alfabeta

Sulaeman,Munandar.2007. Ilmu Budaya Dasar, Suatu Pengantar Bandung: PT Refika Aditama

Syukur Abd, Ahmad.2006. Islamdan Kebudayaan Akulturasi, Nilai-Nilai 
JUPE: Jurnal Pendidikan Mandala

http://ejournal.mandalanursa.org/index.php/JUPE/index
Vol. 4. No. 5 Desember 2019 p-ISSN: 2548-5555 e-ISSN:2656-6745

Islam dalam Budaya Sasak.

Yogyakarta : Adab Press

Zuhdi, Muhammad Harfin dkk. 2011. Lombok

Miras Sasak Adi, Sejarah Sosial,

Islam, Budaya, Politik, dan Ekonomi

Lombok. Jakarta: Imsak Press 